\title{
SIMPLE FIXED SPACE MAINTAINER BONDED WITH FLOWABLE RESIN COMPOSITE IN PREMATURE LOSS OF MAXILLARY FIRST PRIMARY MOLAR (Laporan Kasus)
}

\author{
Herni Primaywati,* Margaretha Suharsini* * \\ *Peserta PPDGS Ilmu Kedokteran Gigi Anak Fakultas Kedokleran Gigi Universitas Indonesia \\ **Departemen Ilmu Kedokteran Gigi Anak Fakultas Kedokteran Gigi Universitas Indonesia
}

\begin{abstract}
Simple Fixed Space Maintainer Bonded with Flowable Resin Composite in Premature Loss of Maxillary First Primary Molar.

The premature loss of primary teeth will make the adjacent tooth drift due to the mesial force of the erupting posterior teeth in the growing child. To overcome this problem a space maintainer is need. But, space maintainer need to undergo a laboratorium process, which means needed more time and money. This paper reported a case with premature loss of maxillary first primary molar using space maintainer which can be used immediately, easy to do. and need low cost. a simple fixed space maintainer bonded with flowable resin composite. Indonesian Journal of Dentistry 2006. Edisi Khusus KPPKG XIV 2006: $129-133$
\end{abstract}

Key words: simple fixed space maintainer, flowable resin composite, premature loss of the primary teeth

\section{Pendahuluan}

Kehilangan dini gigi sulung akan mengakibatkan gigi tetangganya bergeser karena adanya gaya ke mesial dari gigi posterior yang erupsi pada anak yang sedang dalam tahap pertumbuhan dan perkembangan.' Pada kehilangan dini gigi molar sulung dan kegagalan untuk menjaga ruang tersebut selama masa pertumbuhan dan perkembangan akan mempengaruhi oklusi normal pada gigi permanennya. ${ }^{2}$

Alat yang digunakan untuk menjaga ruang akibat kehilangan dini gigi sulung adalah space maintainer. Namun pembuatan space maintainer membutuhkan biaya yang besar untuk proses laboratoriumnya. ${ }^{2,3}$

Pada tulisan ini akan dilaporkan suatu kasus kehilangan dini gigi molar satu sulung rahang atas menggunakan space maintainer yang mudah dan murah dilakukan, yaitu space maintainer cekat sederhana yang direkatkan dengan resin komposit berkemampuan mengalir.

\section{Tinjauan Pustaka}

Indikasi penggunaan space mainfainer adalah apabila terjadi kehilangan gigi sulung dan gigi penggantinya befum siap erupsi menggantikan posisi gigi sulung tersebut dan analisa ruang menyatakan masih terdapat ruang yang memungkinkan untuk gigi permanennya. ${ }^{1,4}$ Apabila terdapat maloklusi dan maloklusi akan bertambah parah dengan adanya kehilangan ruang, maka evaluasi orthodonsia perlu dipertimbangkan.'

Waktu yang tepat untuk penggunaan space maintainer adalah segera setelah kehilangan gigi sulung. Pada kebanyakan kasus penutupan ruang terjadi setelah 6 bulan kehilangan gigi.' 
Kontra indikasi space maintainer adalah tidak terdapat tulang alveolar yang menutup mahkota gigi tetap yang akan erupsi dan kekurangan ruang untuk erupsinya; ruangan yang berlebihan untuk gigi tetapnya erupsi; kekurangan ruang yang sangat banyak sehingga memerlukan tindakan pencabutan dan perawatan orthodonsia dan gigi permanen penggantinya tidak ada.'

Syarat suatu'space maintainer adalah dapat menjaga ruang dimensi proksimal, tidak menggangu erupsi gigi antagonisnya, tidak menggangu erupsi gigi permanen, tidak mempengaruhi fungsi bicara, pengunyahan, dan fungsi pergerakan mandibula, disain yang sederhana, dan mudah dibersihkan.'

Klasifikasi space mainainer menurut Snawder 1980 adalah (1) space maintainer cekat dengan band; (2) space maintainer cekat tanpa band atau dengan etsa asam; (3) space maintainer lepasan dengan bund atau semi-cekat; (4) space maintainer lepasan tanpa band; (5) space maintainer fungsional; dan (6) space maintainer nonfungsional.'

Kekurangan space maintainer adalah (1) cenderung mengakibatkan tipping dan rotasi gigi penyangga: ${ }^{2.4}$ (2) menycbabkan terjadinya retensi plak sehingga terjadi daerah demineralisasi dan karies pada gigi penyangga; ${ }^{3,5}$ (3) membutuhkan preparasi pada gigi penyangga; $;$ (4) membutuhkan waktu kunjungan yang lama; ${ }^{2}$ (5) membutuhkan proses laboratorium yaitu penyolderan; (6) daerah solder mudah rusak; ${ }^{6}$ dan (7) sitotoksik karena terdapat daerah solder. ${ }^{\text {? }}$

Kondisi gigi yang memenuhi syarat untuk pemasangan space maintainer cekat sederhana yang direkatkan dengan resin komposit berkemampuan mengalir adalah (b) kehilangan dini gigi molar sulung; (2) terdapat gigi di mesial dan distal dari ruang gigi yang telah hilang untuk gigi penyangga; dan (3) tidak ada restorasi pada permukaan bukal dari gigi penyangga. Secara radiografis harus memenuhi syarat sebagai berikut (1) tidak ada resorbsi patologis pada gigi penyangga; (2) adanya gigi permanen pengganti: (3) benih gigi permanen pengganti masih tertutup tulang; (4) pembentukan akar gigi permanen péngganti belum selesai; dan (5) tidak ada kondisi patologis pada jalur crupsi gigi permanen pengganti. $^{2}$

Pada tahun 1976, Swaine \& Wright merancang space maintainer yang menggunakan kawat orthodonsia staintess steel penampang bulat berukuran 0,032 inci dengan loop pada kedua ujungnya dan direkatkan dengan resin komposit condensable pada email gigi penyangga. ${ }^{3}$ Dengan menggunakan jenis dan ukuran kawat yang sama, Snawder hanya membuat beberapa groove pada ujung kawat untuk retensi resin kompositnya.' Santos membuat space maintainer sejenis dari kawat stainless steel berpenampang bulal berukuran $0,7 \mathrm{~mm}$ serta groove pada ujungnya dengan tekukan pada regio kchilangan dinj gigi sulung bertujuan untuk menghindari tekanan kunyah pada space mainiainer, menjaga kebersihan mulut, dan tidak menghalangi crupsi gigi permanennya. ${ }^{8}$

Pada tahun 2004, Simsek menggunakan kawat stainless steel berpenampang rektangular dengan tekukan pada regio kehilangan dini gigi sulung yang direkatkan dengan resin komposit berkemampuan mengalir." Lebih jelas dapat dilihat pada Tabel 1.

Tabel 1. Tabel Masam-macam Jenis Space Maintainer yang Direkatkann dengan Resin Komposit.

\begin{tabular}{|c|c|c|c|c|c|}
\hline Itracen & 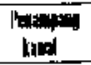 & 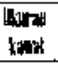 & Hallui & 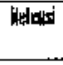 & 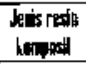 \\
\hline intin & 助始 & 1). 1132 & 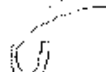 & Way & lianeastile \\
\hline Shriwer & $\mathrm{H}$ Ha & (4) $1013: 2$ & $\cos _{n+\infty}$ & firwine & Contatistede \\
\hline stans & 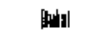 & $11,:$ & ma!! & Honte & 1) \\
\hline 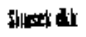 & 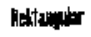 & & an & & a reenty \\
\hline
\end{tabular}

Santos dkk. melakukan penelitian dengan tujuan untuk mengevaluasi secara klinis space maintainer yang dapat segera dipakai atau tanpa prosedur laboratorium, sehingga dapat mengurangi biaya. ${ }^{8}$

Baroni melaporkan kegagalan space maintainer band and loop atau crown and loop rata-rata terjadi setelah $12,5-14$ bulan sekitar $10 \%-11 \%$. $^{2}$ Penelitian oleh Santos melaporkan kegagalan 8,3\% setelah 6 bulan pemakaian space maintainer yang direkatkan dengan resin komposit condensable. ${ }^{8}$ Sedangkan pada penelitian yang dilakukan oleh Simsek dengan tipe space maintainer cekat sederhana yang direkatkan dengan resin komposit berkemampuan mengalir melaporkan kegagalan rata-rata tcrjadi setelah 15,6 bulan sebesar 5\%."

Bahan adesif dan komposit yang digunakan juga sangat mempengaruhi keberhasilan space maintainer tersebut. ${ }^{2}$ Semakin besar kawat yang digunakan, maka akan scmakin sedikit resin komposit yang menempel pada kawat dan gigi, hal ini akan meningkatkan kegagajan space maintainer. ${ }^{8}$ Kegagalan banyak terjadi pada gigi rahang bawah karena kurangnya isolasi saliva selama pemasangan alat dan besarnya tekanan kunyah. Kualitas permukaan email gigi sulung juga mempengaruhi retensi space maintainer. 
Walaupun pada pasien telah dilakukan DHE, tetap ditemukan adanya akumulasi plak pada gigi penyangga, namun tidak ditemukan daerah dekalsifikasi. ${ }^{2,3,8}$

Gigi cenderung akan bergeser ke arah mesial karena adanya fenomena mesial drifting tendency dan gaya gigi posterior yang akan erupsi pada anak yang sedang dalam tahap pertumbuhan dan perkembangan.' Kehilangan dini satu atau lebih gigi sulung, dapat mengakibatkan (1) pergeseran midline, (2) gigi berjejal, (3) perubahan pada lengkung gigi, dan (4) kehilangan ruang untuk gigi tetap penggantinya. ${ }^{2}$

Menurut Hoffding dan Kisling (1978), kehilangan dini gigi molar satu sulung pada maksila akan mengakibatkan berjejalnya gigi posterior dan kehilangan ruang pada mandibula, sedangkan kehilangan dini gigi molar dua sulung baik pada maksila ataupun mandibula akan mengakibatkan perubahan arah horizontal pada hubungan molar permanennya.

Resin komposit berkemampuan mengalir memiliki jumlah filler (bahan pengisi) lebih sedikit daripada resin komposit condensable sehingga viskositasnya menjadi encer, tetapi memiliki jumlah matriks yang sama dengan resin komposit condensable. Sifat mekanis resin komposit akan berkurang apabila bahan pengisi dikurangi, namun dengan bahan pengisi yang halus daya tahan terhadap keausan akan meningkat. Secara umum sifat-sifat mekanis yang meliputi kekuatan kompresi, kekuatan tarik, kekuatan flexural dan toughness dari berbagai resin komposit berkemampuan mengalir lebih rendah, namun tidak berbeda bermakna bila dibandingkan dengan resin komposit condensable. ${ }^{10}$

Sesuai dengan namanya, resin komposit berkemampuan mengalir memiliki sifat thixotropik yaitu kemampuan untuk beradaptasi pada kavitas dan daerah yang sulit dicapai dengan bahan resin komposit condensable, selain itu juga untuk mengurangi gelembung udara yang dapat terjebak pada saat aplikasi bahan. ${ }^{10,11}$

\section{Laporan Kasus}

Pasien laki-laki usia 7 tahun, datang pada tanggal 12 Oktober 2005. Pada saat datang pasien masih dalam periode gigi sulung. Pada mulut pasien ditemukan sisa akar gigi molar satu sulung rahang atas kiri (64), karies dentin permukaan distal gigi 63, dan karies dentin permukaan mesial dan oklusai pada gigi 65 (Gambar 1). Tidak terdapat maloklusi dengan hubungan molar sulung adalah mesial step.

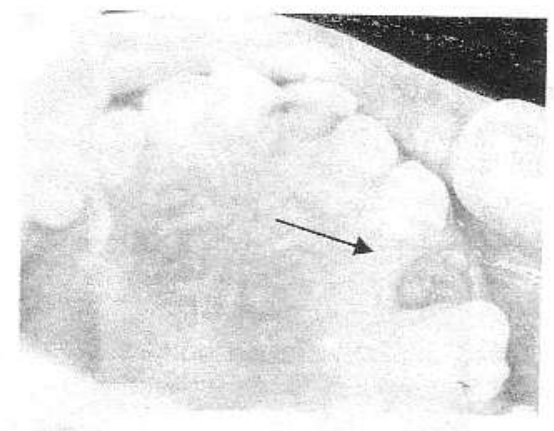

Gambar 1. Gigi 64 sisa akar

Gambaran radiografik gigi 64 adalah sisa akar, resorbsi akar mencapai 1/3 apikal, terdapat radiolusensi di periapeks, pembentukan benih 24 mencapai $1 / 3$ servikal akar dan belum menembus tulang, pada gigi 63 dan 65 tidak terdapat resorbsi patologis, dan benih gigi 26 siap untuk erupsi (Gambar 2).

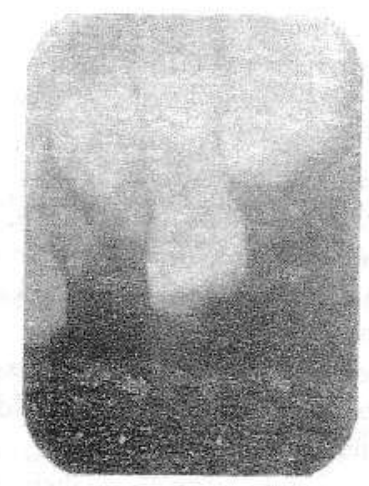

Gambar 2. Gambaran radiograf sebelum ekstraksi 64

Setelah diberi pendidikan kesehatan gigi dan terapi propilaksis oral, gigi 63 dan 65 direstorasi dengan SIK dan pada tanggal 20 Oktober 200564 diekstraksi. Pada tanggal 29 Oktober 2005 dilakukan pencetakan untuk pedoman pembuatan alat. Space maintainer dibuat dengan bahan kawat stainless steel rektangular $0,016 \times 0,022$ inci, dengan tekukan pada regio 64.

Alat dipasang pada tanggal 12 Nopember 2005. Kawat space maintainer jangan sampai menekan gingiva, tetapi berada $0,5-1 \mathrm{~mm}$ di atas mukosa gingiva. Prosedur pemasangan space maintainer adalah: etsa email permukaan bukal gigi 63 dan 65 dengan asam fosfat, bilas etsa dengan air, keringkan, aplikasikan bahan adesif (Prime and Bond, Dentsply), disinar, aplikasikan resin komposit berkemampuan mengalir (CharmFil Flow, DentKist), letakkan kawat space maintainer dengan posisi lengan pada resin komposit, dan disinar (Gambar 3). 


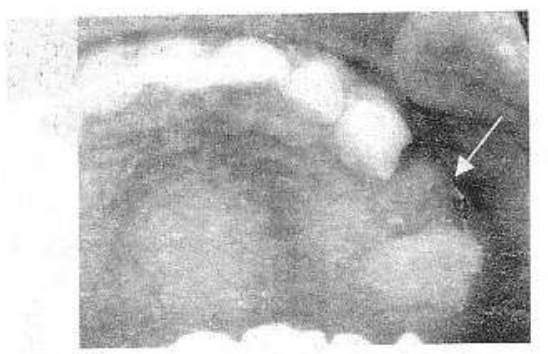

a

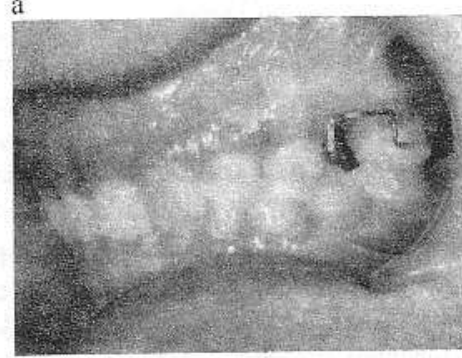

b

Gambar 3a-b. Space maintainer setelah direkatkan

Pasien diminta untuk datang kontrol 1 minggu kemudian, namun pasien baru dapat datang untuk kontrol 1 bulan kemudian (16 Desember 2005). Setiap kali pasien datang untuk kontrol, dilakukan pemeriksaan keutuhan space maintainer, kondisi gigi penyangga, dan gingivanya. Pada gigi penyangga ditemukan plak, namun tidak ditemukan daerah dekalsifikasi atau karies. Kondisi gingiva pasien baik, salah satu sudut space maintainer berkontak ringan pada gingiva, dain tidak terdapat kemerahan. Pasien diinstruksikan untuk terus menjaga kebersihan mulutnya dan operator juga melakukan profilaksis oral. Kontrol terakhir adalah tanggal 10 Maret 2006 (Gambar 4).

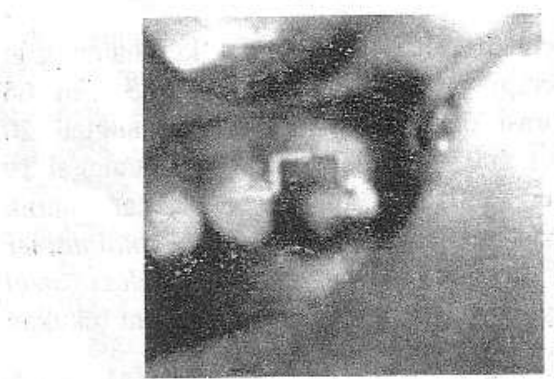

Gambar 4. Kontrol setelah 4 bulan pemasangan

\section{Pembahasan}

Pasien adalah anak usia 7 tahun dengan gigigeligi masih dalam periode gigi sulung, tidak terdapat maloklusi dan malposisi pada gigi lainnya, namun ditemukan sisa akar pada gigi 64. Gigi penggantinya yaitu 24 belum siap untuk erupsi menggantikan posisi gigi sulung tersebut. Secara radiografis pembentukan benih 24 mencapai $1 / 3$ servikal akar, dan masih tertutup tulang. Dari analisis ruang secara radiografis terlihat masih terdapat ruang yang memungkinkan gigi 24 untuk erupsi (Gambar 2). Kondisi tersebut merupakan indikasi pembuatan space maintainer., ${ }^{1,9}$

Waktu yang tepat bagi penggunaan space maintainer adalah segera setelah kehilangan gigi sulung. Pada kebanyakan kasus penutupan ruang terjadi 6 bulan setelah kehilangan gigi. ${ }^{1}$ Santos melakukan penelitian dengan mengevaluasi space maintainer yang segera dipasangkan pada pasien tanpa melakukan pencetakan dan proses laboratorium. ${ }^{8}$ Pada kasus ini jarak waktu antara tindakan ekstraksi gigi 64 dengan pemasangan space maintainer adalah 3 minggu. Hal ini disebabkan keterbatasan keterampilan operator, alat dan bahan, serta keterbatasan waktu pasien untuk datang ke klinik.

Pencetakan model kerja dilakukan sebagai pedoman bagi pembuatan space maintainer. Space maintainer dibuat dengan tekukan pada regio kehilangan dini gigi 64 untuk menghindari tekanan kunyah pada space maintainer, menjaga kebersihan mulut pasien, dan tidak menghalangi erupsi gigi permanennya.. ${ }^{2.8}$

Pemilihan space maintainer cekat berdasarkan pada adanya kehilangan dini unilateral gigi sulung posterior yaitu molar satu sulung rahang atas kiri, kerjasama yang baik dari pasien, dan kebersihan mulut yang baik. Kondisi ini adalah indikasi untuk pembuatan space maintainer cekat band and loop.Error! Bookmark not defined. Pemilihan jenis space maintainer pada kasus ini adalah space maintainer cekat sederhana yang direkatkan dengan resin komposit berkemampuan mengalir yang mudah dan murah, sesuai dengan penelitian Simsek. ${ }^{2}$

Syarat untuk pemasangan space maintainer cekat sederhana yang direkatkan dengan komposit resin berkemampuan mengalir adalah (1) kehilangan dini gigi molar sulung; (2) terdapat gigi di mesial dan distal dari ruang gigi yang telah hilang untuk gigi penyangga; dan (3) tidak ada restorasi pada permukaan bukal gigi penyangganya. ${ }^{2}$ Kondisi gigi pasien pada gigi 63 dan 65 terdapat karies dentin pada permukaan distal, mesial, oklusal dan sudah direstorasi dengan SIK. Hal ini memenuhi syarat sesuai dengan penelitian sebelumnya.

Selain itu secara radiografis terlihat (1) tidak ada resorbsi patologis pada gigi penyangga yaitu 63 dan 65 ; (2) adanya gigi permanen pengganti yaitu gigi 24 , (3) benih gigi 24 masih tertutup tulang; (4) pembentukan akar gigi permanen pengganti (24) belum 
selesai; dan (5) tidak ada kondisi patologis pada jalur erupsi gigi permanen pengganti. ${ }^{2}$

Space maintainer cekat sederhana yang direkatkan dengan resin komposit berkemampuan mengalir dibuat dengan menggunakan kawat orthodonsia stainless steel berpenampang rektangular dengan ukuran $0,016 \times 0,022$ inci yang dibentuk dengan tekukan pada regio kehilangan dini gigi 64. Kawat jenis stainless steel dipilih karena kawat tersebut dapat dibentuk sesuai kebutuhan. Ukuran kawat dipilih yang kecil dengan pertimbangan ada tempat untuk resin kompositnya. ${ }^{8}$ Pada kasus ini dipilih penampang kawat rektangular agar tidak terjadi rotasi kawat pada sumbunya.

Pada kontrol 1 bulan setelah pemasangan, terlihat space maintainer tetap baik pada tempatnya dan terdapat retensi plak pada gigi penyangga. Hal ini sesuai dengan penelitian yang sudah dilakukan. ${ }^{2,3,8}$ Maka pasien diinstruksikan untuk meningkatkan kebersihan mulutnya.

Pada kontrol setelah 4 bulan pemasangan, terlihat space maintainer masih terpasang baik pada rongga mulut pasien. Tidak ditemukan kerusakan pada space maintainer, kelainan gingiva sekitar, dan karies pada permukaan gigi daerah perlekatan space maintainer (Gambar 4). Hal ini sesuai dengan penelitian yang dilakukan oleh Simsek yang menggunakan tipe space maintainer cekat sederhana yang direkatkan dengan resin komposit berkemampuan mengalir; mereka melaporkan kegagalan rata-rata terjadi setelah 15,6 bulan sebesar $5 \%{ }^{2}$

Bahan adesif dan komposit yang digunakan juga sangat mempengaruhi keberhasilan space maintainer tersebut. ${ }^{2}$ Pada kasus ini menggunakan bahan adesif dengan merk dagang Prime and Bond (Dentsply), resin komposit berkemampuan mengalir dengan merk dagang Charm Fil Flow (Dent Kist).

Pada setiap kali kontrol, pasien diberi DHE karena ditemukan akumulasi plak pada permukaan gigi penyangga. Tindakan ini bertujuan agar tidak terjadi karies pada daerah tersebut. $\mathrm{Hal}$ ini sesuai dengan penelitian sebelumnya yaitu ditemukannya plak, namun tidak ditemukan daerah dekalsifikasi atau karies pada gigi penyangga. ${ }^{2,8}$

Pada saat datang, pasien berusia 7 tahun dan masih dalam tahap periode gigi sulung. Dari gambaran radiografis terlihat bahwa benih gigi 26 siap untuk erupsi, sehingga diperlukan space maintainer untuk mempertahankan ruangan akibat kehilangan dini gigi 64 agar tidak terjadi penutupan ruang akibat fenomena mesial drifting tendency dan gaya dari gigi 26 yang akan erupsi. ${ }^{1}$ Space maintainer dibuat untuk mencegah terjadinya pergeseran midline, berjejalnya gigi posterior, kehilangan ruang pada mandibula, perubahan pada lengkung gigi, dan kehilangan ruang untuk gigi tetap penggantinya. ${ }^{2,9}$

Penggunaan resin komposit berkemampuan mengalir mempermudah aplikasi karena memiliki sifat thixotropik yaitu kemampuan untuk beradaptasi pada kavitas dan daerah yang sulit dicapai dengan bahan resin komposit condensable, selain itu juga untuk mengurangi gelembung udara yang dapat terjebak pada saat aplikasi bahan. ${ }^{10,11}$

\section{Kesimpulan}

Space maintainer merupakan suatu alat yang diperlukan untuk menjaga ruangan akibat kehilangan dini gigi sulung. Salah satu jenis space maintainer yaitu space maintainer cekat sederhana yang direkatkan dengan resin komposit berkemampuan mengalir dapat menjadi pertimbangan pilihan perawatan bagi kasus kehilangan dini gigi sulung karena space maintainer ini murah, dapat segera dipasangkan, dan mudah dikerjakan oleh dokter gigi.

\section{Daftar Acuan}

1. Snawder KD. Handbook of Clinical Pedodontics. St. Louis: Mosby Co., 1980.

2. Simsek S. Clinical Evaluation of Simple Fixed Space Maintainers Bonded with Flow Composite Resin. Dent Child 2004; 71:163-8.

3. Swaine T, Wright GZ. Direct Bonding Applied to Space Maintenance. J Dent Child 1976; 43:401-5.

4. Finn SB. Clinical Pedodontics $4^{\text {th }}$ ed. Philadelphia: WB Saunders Co., 1973

5. Kisling E \& Hoffding J. Premature Loss of Primary Teeth: Part IV, a Clinical Control of Sannerud's Space Maintainer, Type I. J Dent Child 1979; 46:17-21.

6. Prush RJ. The Use of Stainless Steel Crowns in the Construction of Space Maintainers. J Dent Child 1978; 45:37-39.

7. Hill CJ, Sorenson HW, Mink JR. Space Maintenance in A Child Dental Program. J Am Dent Assoc 1975; 90; $811-5$.

8. Mockers O, Deroze D, Camps J. Cytotoxicity of Orthodontics Bands, Brackets and Archwires in vitro. Dent Mater 2002; 18:311-7.

9. Santos VLC, et al. Direct Bonded Space Maintainer. $J$ Clinical Pediatr Dent. 1993; 4:221-5.

10. Hoffding J, Kisling E. Premature Loss of Primary Teeth Part II, The Specific Effect on Occlusion and Space in the Permanent Dentition. J Dent Child 1978; 45: 284-7.

11. Bayne SC. A Characterization of First Generation Flowable Composites. J Am Dent Assoc 1998; 129:567. 77.

12. Opdam NJ. Cavity Wall Adaptation and Vords in Adhesive Class I Resin Composite Restorations. Dent Mater 1996; 12: 230-5 